\title{
Caminata y vejez: explorando el espacio público peatonal de las personas mayores en los instrumentos de planificación urbana en Chile
}

\author{
Caminhada e velhice: Explorando o espaço público pedestre das \\ pessoas idosas nos instrumentos de planificação urbano no Chile \\ Walking and ageing: exploring the walkable public space of \\ older adults in Chilean' urban planning tools
}

Marie Geraldine Herrmann-Lunecke [a] [D, Cristhian Figueroa Martínez [b] [D],

Paloma Vejares Salgado [c] [D

[a] Universidad de Chile, Departamento de Urbanismo, Santiago, Chile

[b] University of Leeds, Institute for Transport Studies, Leeds, Reino Unido

[c] Universidad Diego Portales, Escuela de Arquitectura, Santiago, Chile

Cómo citar: Herrmann-Lunecke, M. G., Figueroa, C., \& Vejares, P. (2021). Caminata y vejez: explorando el espacio público peatonal de las personas mayores en los instrumentos de planificación urbana en Chile. urbe. Revista Brasileira de Gestão Urbana, v.13, e20210128. https://doi.org/10.1590/2175-3369.013.e20210128

\section{Resumen}

El envejecimiento es uno de los desafíos más relevantes que enfrentan las ciudades latinoamericanas, pero poco se conoce sobre cómo ese desafío es abordado por la planificación urbana. Este artículo busca avanzar en aquella discusión, indagando en cómo los instrumentos que definen el espacio público peatonal de las ciudades chilenas recogen las necesidades de las personas mayores y, en general, de los peatones. Con herramientas de análisis cualitativo, se estudiaron quince instrumentos normativos e indicativos cuyo contenido evidenció que las personas mayores son escasamente consideradas en espacios públicos que priorizan la fluidez de un peatón "promedio" y en constante movimiento.

Palabras clave: Personas mayores. Caminata. Entorno construido. Planificación urbana. Grupos vulnerados.

\section{Resumo}

O envelhecimento é um dos desafios mais relevantes que enfrentam as cidades de américa latina, mas pouco se conhece sobre como esse desafio é enfrentado pela planificação urbana. Este artigo procura avançar nessa discussão, pesquisando em como os instrumentos que definem o espaço pedestre das cidades chilenas, eles coletam as necessidades das pessoas maiores e, em general, dos pedestres. Com ferramentas de análise qualitativo, eles estudaram quinze instrumentos normativos e indicativos cujo conteúdo evidenciado que as pessoas maiores são dificilmente consideradas em espaços que priorizam a fluência de um pedestre "média" e em movimento.

Palavras-chave: Pessoas maiores. Caminhada. Ambiente construído. Planificação urbana. Grupos vulneráveis.

\begin{abstract}
Population ageing is one of the biggest challenges of Latin American cities, yet little is known on how urban planning addresses it. This article seeks to contribute to this discussion, by investigating how the planning tools that define the
\end{abstract}

MGHL es arquitecta, doctora en Urbanismo, e-mail: mherrmann@uchile.cl

CFM es arquitecto, PhD in Transport Studies, e-mail: cofiguer@gmail.com

PVS es arquitecta, Licenciada en Arquitectura, e-mail: paloma.vejares@gmail.com 
walkable space of Chilean cities cover the needs of older adults and, in general, of pedestrians. Fifteen normative and indicative tools were analysed with qualitative tools, showing that older people's needs are scarcely considered in public spaces that prioritise the flow of an "average" and in constant movement pedestrian.

Keywords: Older adults. Walking. Built environment. Urban planning. Vulnerable groups.

\section{Introducción}

Las personas mayores son un grupo diverso. Son, en su mayoría, autovalentes y poseen distintas capacidades de acuerdo a sus trayectorias personales, capital social, recursos disponibles, etc. (World Health Organization - WHO, 2015). Son un grupo vulnerado; afectado por una serie de estigmas que suelen "fragilizarlos" (e.g., edadismo) e invisibilizarlos y que tiende a sufrir distintas formas de pobreza (United Nations Department of Economic and Social Affairs - UN DESA, 2015; Warmoth et al., 2016; Bravo-Segal, 2018). Debido a dispares esperanzas de vida, las personas mayores son un grupo compuesto por más mujeres que hombres y cuyo estudio requiere de perspectivas de género (Barrantes, 2006; UN DESA, 2020). En un mundo en rápido envejecimiento y con esperanzas de vida cada vez más elevadas, las personas mayores son un grupo clave en las políticas públicas que, con distintas estrategias, buscan promover un envejecimiento más activo y saludable (Marín, 2007; WHO, 2020).

Por sus múltiples beneficios, la caminata es usualmente representada como un elemento esencial de la vida de las personas (Lorimer, 2011). Demerath y Levinger (2003) e Ingold y Vergunst (2008) apuntan que la caminata permite acceder al dominio público; es un medio que facilita el ejercicio de derechos ciudadanos, la apropiación de los territorios y propicia la construcción de redes sociales y la reproducción de capital social. Deka y Brown (2020) y Lee y Buchner (2008) agregan que la caminata mejora la salud física y mental y la calidad de vida de las personas y ayuda a prevenir dolencias crónicas que disminuyen la funcionalidad. Es una práctica compleja, que tiene un papel fundamental en el proceso de envejecimiento y en la visibilidad de las necesidades y las demandas de los mayores (Barnett et al., 2017; Salvo et al., 2018).

La caminata ocurre en interacción con su entorno. Al respecto, existe un abundante cuerpo de literatura que indica que usos de suelo mixtos, diseños urbanos amigables al peatón, tramas urbanas conexas, entre otros, promueven la actividad física y propician la caminata (Garin et al., 2014; Barnett et al., 2017; Salvo et al., 2018). Indagando en las prácticas cotidianas de las personas mayores, varios autores agregan que espacios hostiles (e.g., cruces peligrosos, veredas desniveladas) pueden provocar caídas, accidentes y afectar la percepción de riesgo (Clarke et al., 2008; Nyman et al., 2013). Otros trabajos enfatizan la relevancia de la calidad del espacio peatonal en la percepción de las personas; pudiendo acrecentar miedos y hacer de la caminata una experiencia difícil (Yen at al., 2014; Ferrer et al., 2015; Herrmann-Lunecke et al., 2021). Al contrario, la presencia de amenidades para el peatón (e.g., bancas) y de elementos placenteros (e.g., vegetación) pueden volver a la caminata una actividad grata e incentivarla (Mitra et al., 2015; Cano \& Sánchez-González, 2019). Mientras que, estudiando manuales y buenas prácticas, Higueras et al. (2021) sugieren que las estrategias que buscan promover ciudades saludables para las personas mayores han estado orientadas principalmente a generar barrios caminables y seguros, espacios verdes y lugares en donde exista contacto intergeneracional.

En este contexto, el presente artículo tiene como objetivo analizar en qué medida los instrumentos de planificación urbana chilenos abordan la caminata en la vejez y consideran a las personas mayores en el diseño del espacio público destinado al peatón ("espacio público peatonal”, ver Herrmann-Lunecke, 2016). Con este fin, se estudiaron diez instrumentos de carácter normativo y cinco indicativos, aislando fragmentos que hacen referencia a las personas mayores y otros grupos vulnerados (e.g., niños), el peatón y los elementos del entorno que definen el espacio público peatonal (e.g., veredas). Luego, se analizó el contenido de los fragmentos con el fin de caracterizar las variables antes nombradas y las formas en que recogen las necesidades de las personas mayores y, en general, de los peatones.

El artículo se enfoca en Chile, un país en "transición demográfica avanzada” y uno de los más envejecidos de Latinoamérica (Apella et al., 2019). Mediante el estudio del caso chileno, el artículo busca visibilizar las dificultades que enfrentan las personas mayores en una de las regiones que más rápido envejece en el mundo 
(Aranco et al., 2018). Se busca discutir cómo los instrumentos que definen el espacio público peatonal recogen las necesidades de las personas mayores en ciudades que sufren de profundas desigualdades. Asimismo, se persigue complementar los estudios sobre el espacio público peatonal y que, hasta el momento, se han ocupado principalmente de identificar los atributos físicos que incentivarían una vida más activa en las personas mayores (Gómez et al., 2010; Gomes et al., 2011; Arango et al., 2013).

El presente artículo se estructura en cuatro partes. La siguiente sección (sección 2) contiene una breve caracterización de las personas mayores en Chile y de los obstáculos que enfrentan en el espacio público peatonal. En la sección 3 se detalla la aproximación metodológica que se utilizó para analizar los instrumentos. La sección 4 incluye los principales hallazgos del estudio y se encuentra subdivida en tres subsecciones que abordan: la situación de las personas mayores y otros grupos vulnerados (sección 3.1), las formas en las que se comprende al peatón (sección 3.2) y las características y atributos del espacio público peatonal según los instrumentos de planificación urbana (Sección 3.3). Una última sección (Sección 4) incluye las principales conclusiones del artículo.

\section{Personas mayores y espacio público peatonal en Chile}

En Chile las personas mayores (65 años o más) representan un 12\% (2.26 millones) de la población total (Instituto Nacional de Estadística - INE, 2018). Con una de las esperanzas de vida más elevadas de la región (80 años, Banco Mundial, 2018), se espera que aquel porcentaje se eleve al 25\% hacia el año 2050 (INE, 2018). Según la Subsecretaría de Evaluación Social (2020), un tercio de las personas mayores del Chile actual trabaja y casi un cuarto (22\%) sufre de pobreza multidimensional. La "Encuesta de Calidad de Vida en la Vejez" (Pontificia Universidad Católica de Chile - PUC-Chile \& Caja Los Andes, 2020) agrega que casi un quinto de la población mayor vive sola (18\%), poco más de la mitad con sus parejas (52\%); cerca de un cuarto considera que no tiene amigos cercanos (25,2\%); casi un quinto cuida a sus nietos y uno de cada diez (9\%) se hace cargo de una persona enferma, usualmente su pareja, siendo un grupo que participa activamente en trabajos del cuidado. La misma encuesta indica que la mitad declara sufrir de alguna dolencia que afecta su vida cotidiana, cerca de tres cuartos $(72 \%)$ indica que no realiza ninguna forma de actividad física de manera regular y menos de un quinto (17\%) camina más de catorce cuadras (1.4 km aproximadamente) al día. Finalmente, en una escala de 1 a 7 , las personas mayores no evalúan ningún aspecto de las ciudades chilenas sobre 5 (PUC-Chile y Caja Los Andes, 2020) ${ }^{1}$.

El estado chileno ha ratificado una serie de acuerdos que velan por los derechos, la dignidad y el bienestar de las personas mayores (Organización de las Naciones Unidas - ONU, 2003; Comisión Económica para América Latina y el Caribe - CEPAL, 2007; Organización de los Estados Americanos - OEA, 2015). El país también participa en iniciativas que buscan generar entornos adecuados para las personas mayores (e.g., WHO, 2018) y posee programas que buscan promover formas saludables de envejecimiento (e.g., Ministerio de Salud MINSAL, 2016; Servicio Nacional del Adulto Mayor - SENAMA, 2019). Sin embargo, las personas mayores aún sufren de vulneraciones (e.g., estigmas, ver Adams, 2012; Abusleme y Caballero, 2014) que, en una sociedad altamente desigual como la chilena, suelen ser más severas en los grupos de menores recursos (Albala et al., 2011; Fuentes-García et al., 2013). A esto se suma que el entorno urbano muchas veces representa un obstáculo para las personas mayores (Osorio et al., 2008). Así, a pesar de que el país ha avanzado en la provisión de servicios y la eliminación de la informalidad en las ciudades (Caldeira, 2017; Figueroa et al., 2019), el espacio público aún es deficitario y de una desigual calidad, siendo, una barrera para la movilidad de las personas mayores y de otros grupos como niños, mujeres y personas en situación de discapacidad (Fadda y Cortés, 2009; Figueroa y Forray, 2015; Gaete-Reyes, 2017; Waintrub, 2018). Cruces peligrosos, tiempos semafóricos reducidos, veredas en mal estado, carencias de servicios (e.g., servicios higiénicos), entre otros, son comunes en las ciudades chilenas y representan un desafío para las personas mayores, inhibiendo los desplazamientos y promoviendo la inmovilidad (González, 2004; Espinosa et al., 2015; Herrmann-Lunecke, 2016; Olivi et al.,

\footnotetext{
${ }^{1}$ En el contexto socio-cultural chileno, una calificación bajo 5 es considerada mediocre o baja.
} 
2016; Herrmann-Lunecke et al., 2021; Vecchio et al., 2020). Tal como indican Gajardo et al., (2012) investigando el transporte público en Santiago, la capital del país, mucho de la vida cotidiana de las personas mayores transcurre con relativa normalidad debido a redes sociales de apoyo robustas más que por las facilidades que encuentran en las ciudades.

\section{Métodos y materiales}

El objetivo de la presente investigación es analizar en qué medida los instrumentos de planificación urbana consideran a las personas mayores en el diseño del espacio público peatonal. Con este fin se identificaron y analizaron aquellos instrumentos que regulan el espacio público peatonal en Chile. Como muestra la Tabla 1, esto incluye una política nacional que define los lineamientos que las ciudades chilenas debiesen seguir (Gobierno de Chile y Programa de las Naciones Unidas para el Desarrollo - PNUD, 2014) y siete instrumentos normativos que regulan las características de las calles (Ministerio de Obras Públicas MOP, 1949; Ministerio de Transportes y Telecomunicaciones - MTT, 2018; Ministerio de Vivienda y Urbanismo - MINVU, 1992), los conflictos entre los distintos medios de transporte (Ministerio de Justicia, 1984; MTT, 2018) y la inclusión de personas en situación de discapacidad y movilidad reducida (MINVU, 2016; Ministerio de Planificación, 2010). Se identificaron también dos manuales que tienen carácter normativo que regulan el diseño vial (MINVU, 2009) y las características de los cruces vehiculares (MTT, 2015) y cinco instrumentos indicativos. Cabe destacar que ninguno de los instrumentos normativos identificados se centra en el espacio peatonal.

Tabla 1 - Instrumentos que definen y regulan el espacio público peatonal en Chile

\begin{tabular}{|c|c|}
\hline $\begin{array}{l}\text { Instrumento } \\
\text { Autor }\end{array}$ & $\begin{array}{l}\text { Fecha de publicación } \\
\text { (última modificación) }\end{array}$ \\
\hline \multicolumn{2}{|l|}{ Leyes y decretos } \\
\hline $\begin{array}{l}\text { Ley } 8.946 \text { - Ley de pavimentación comunal } \\
\text { Ministerio de Obras Públicas (MOP) }\end{array}$ & $1949(2018)$ \\
\hline $\begin{array}{l}\text { Decreto con Fuerza de Ley } 458 \text { - Ley General de Urbanismo y Construcciones } \\
\text { Ministerio de Vivienda y Urbanismo (MINVU) }\end{array}$ & $1976(2020)$ \\
\hline $\begin{array}{l}\text { Ley } 18.290 \text { - Tránsito } \\
\text { Ministerio de Justicia }\end{array}$ & $1984(2020)$ \\
\hline $\begin{array}{l}\text { Decreto Supremo } 47 \text { - Ordenanza General de Urbanismo y Construcciones } \\
\text { Ministerio de Vivienda y Urbanismo (MINVU) }\end{array}$ & $1992(2020)$ \\
\hline $\begin{array}{l}\text { Ley } 20.422 \text { - Igualdad de oportunidades e inclusión social de personas con discapacidad } \\
\text { Ministerio de Planificación }\end{array}$ & $2010(2020)$ \\
\hline $\begin{array}{l}\text { Decreto Supremo } 50 \text { - Accesibilidad Universal } \\
\text { Ministerio de Vivienda y Urbanismo (MINVU) }\end{array}$ & 2016 \\
\hline $\begin{array}{l}\text { Ley } 21.088 \text { - Convivencia Medios de Transporte } \\
\text { Ministerio de Transportes y Telecomunicaciones (MTT) }\end{array}$ & $2018(2020)$ \\
\hline \multicolumn{2}{|l|}{ Manuales (normativos) } \\
\hline $\begin{array}{l}\text { Recomendaciones para el diseño de elementos de infraestructura vial urbana (REDEVU) } \\
\text { Ministerio de Vivienda y Urbanismo (MINVU) }\end{array}$ & 1984 (reeditado en 2009) \\
\hline $\begin{array}{l}\text { Manual de Señalización de Tránsito } \\
\text { Ministerio de Transportes y telecomunicaciones (MTT) }\end{array}$ & 2015 \\
\hline \multicolumn{2}{|l|}{ Política nacional (normativa) } \\
\hline $\begin{array}{l}\text { Política Nacional de Desarrollo Urbano } \\
\text { Gobierno de Chile y Programa de Naciones Unidas para el Desarrollo (PNUD) }\end{array}$ & 2014 \\
\hline \multicolumn{2}{|l|}{ Manuales (indicativos) } \\
\hline $\begin{array}{l}\text { Manual de accesibilidad universal } \\
\text { Corporación Ciudad Accesible y Boudeguer \& Squella ARQ }\end{array}$ & 2010 \\
\hline $\begin{array}{l}\text { Diseño universal en el espacio público } \\
\text { Servicio de Vivienda y Urbanismo Región Metropolitana (SERVIU RM) }\end{array}$ & 2013 \\
\hline $\begin{array}{l}\text { Manual de prevención de caídas en el adulto mayor } \\
\text { Ministerio de Salud (MINSAL) }\end{array}$ & 2015 \\
\hline $\begin{array}{l}\text { La dimensión humana del espacio público } \\
\text { Programa de Naciones Unidas para el Desarrollo (PNUD) y Ministerio de Vivienda y Urbanismo (MINVU) }\end{array}$ & 2017 \\
\hline $\begin{array}{l}\text { Guía de soluciones accesibles para espacios públicos y viviendas } \\
\text { Ministerio de Vivienda y Urbanismo (MINVU) }\end{array}$ & 2018 \\
\hline
\end{tabular}

Fuente: elaboración propia. 
Con una aproximación orientada al descubrimiento (Fossey et al., 2002), se revisaron estos instrumentos y se importaron al software de análisis cualitativo atlas.ti (versión 8.0). Utilizando las herramientas de dicho software, se aislaron aquellos fragmentos que referencian a (i) las personas mayores u otros grupos vulnerados, (ii) los peatones, (iii) el espacio público peatonal y sus distintos elementos y características. De acuerdo a su contenido, se le asignaron etiquetas (códigos) a los fragmentos y luego se agruparon en categorías mayores formando una estructura de "árbol". Los instrumentos fueron analizados de manera independiente por dos miembros del equipo (doble codificación, ver O'Connor y Joffe, 2020), siendo las etiquetas finales el resultado de la comparación y discusión de todo el equipo de investigación en una serie de reuniones de triangulación (agosto a diciembre, 2020). Como resultado de este proceso se identificaron 452 códigos que fueron agrupados en nueve categorías (Tabla 2).

Tabla 2 - Códigos y categorías identificados. En paréntesis número de fragmentos identificados en cada categoría

\begin{tabular}{|c|c|c|c|}
\hline & Categoría & Subcategorías & Códigos (ejemplos) \\
\hline 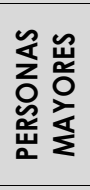 & $\begin{array}{l}\text { 1. Personas: características y derechos } \\
\text { (398) }\end{array}$ & $\begin{array}{l}\text { 1.1. Rango etario (28) } \\
\text { 1.2. Género (4) } \\
\text { 1.3. Vulnerabilidad y discapacidad (280) } \\
\text { 1.4. Otras características (4) } \\
\text { 1.5. Derechos (82) }\end{array}$ & $\begin{array}{l}\text { Adulto mayor, niño, } \\
\text { discapacidad, } \\
\text { discriminación }\end{array}$ \\
\hline $\begin{array}{l}\text { 岁 } \\
\text { 인 } \\
\text { 竞 }\end{array}$ & 2. Actividades de los peatones (33) & $\begin{array}{l}\text { 2.1. Provisión y trabajo (5) } \\
\text { 2.2. Recreación (10) } \\
\text { 2.3. Deportes (1) } \\
\text { 2.4. Interacciones sociales (7) } \\
\text { 2.5. Descanso y espera (10) }\end{array}$ & $\begin{array}{l}\text { Trabajar, comprar, } \\
\text { mirar, sentarse }\end{array}$ \\
\hline \multirow{7}{*}{ 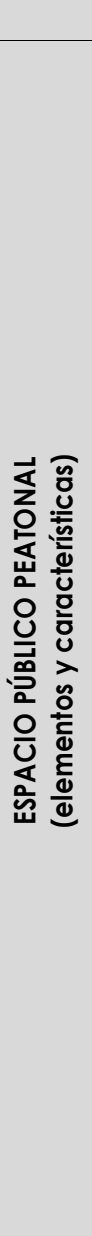 } & 3. Flujos y conflictos (418) & $\begin{array}{l}\text { 3.1. Flujo peatonal (245) } \\
\text { 3.2. Flujo de ciclos (53) } \\
\text { 3.3. Flujo motorizado (75) } \\
\text { 3.4. Flujo animal (5) } \\
\text { 3.5. Conflictos (40) }\end{array}$ & $\begin{array}{l}\text { Caminata, peatón, } \\
\text { caída, demoras, } \\
\text { conflicto peatón- } \\
\text { vehículo. }\end{array}$ \\
\hline & 4. Superficies de circulación (634) & $\begin{array}{l}\text { 4.1. Diseño vial (20) } \\
\text { 4.2. Espacio vehicular (252) } \\
\text { 4.3. Espacio peatonal (362) }\end{array}$ & $\begin{array}{l}\text { Vialidad, ciclovía, } \\
\text { acera }\end{array}$ \\
\hline & $\begin{array}{l}\text { 5. Elementos que dan continuidad al } \\
\text { espacio público peatonal ( } 427)\end{array}$ & $\begin{array}{l}\text { 5.1. Dispositivos que salvan desniveles (157) } \\
\text { 5.2. Cruces peatonales ( } 270 \text { ) }\end{array}$ & Rampa, bandejón. \\
\hline & $\begin{array}{l}\text { 6. Elementos verticales del espacio } \\
\text { público peatonal (395) }\end{array}$ & $\begin{array}{l}\text { 6.1. Elementos de apoyo (15) } \\
\text { 6.2. Mobiliario urbano (99) } \\
\text { 6.3. Postes y luminarias (28) } \\
\text { 6.4. Señalética (118) } \\
\text { 6.5. Elementos de segregación (24) } \\
\text { 6.6. Obstáculos (66) } \\
\text { 6.7. Vegetación (45) }\end{array}$ & $\begin{array}{l}\text { Baranda, baño público, } \\
\text { banca, luminaria, } \\
\text { semáforo }\end{array}$ \\
\hline & $\begin{array}{l}\text { 7. Bordes del espacio público peatonal } \\
\text { (167) }\end{array}$ & $\begin{array}{l}\text { 7.1. Bordes y fachadas (56) } \\
\text { 7.2. Espacios interiores ( } 30) \\
\text { 7.3. Comunicación interior-exterior (81) }\end{array}$ & $\begin{array}{l}\text { Antejardín, terraza, } \\
\text { mobiliario }\end{array}$ \\
\hline & $\begin{array}{l}\text { 8. Tipos de espacios públicos y privados } \\
\text { (326) }\end{array}$ & $\begin{array}{l}\text { 8.1. Calles (161) } \\
\text { 8.2. Plazas, parques y áreas verdes ( } 31 \text { ) } \\
\text { 8.3. Otros lugares (19) } \\
\text { 8.4. Tipos de equipamientos (12) } \\
\text { 8.5. Tipos de edificaciones (6) } \\
\text { 8.6. Tipos de áreas y usos de suelo (97) }\end{array}$ & $\begin{array}{l}\text { Calle peatonal, paseo, } \\
\text { parque, esquina, área } \\
\text { verde }\end{array}$ \\
\hline & $\begin{array}{l}\text { 9. Atributos y beneficios del espacio } \\
\text { público (382) }\end{array}$ & $\begin{array}{l}\text { 9.1. Accesibilidad (66) } \\
\text { 9.2. Seguridad (91) } \\
\text { 9.3. Atributos estéticos (43) } \\
\text { 9.4. Atributos ambientales (47) } \\
\text { 9.5. Atributos sociales y vida pública (5) } \\
\text { 9.6. Integración e inclusión (41) } \\
\text { 9.7. Reproducción del capital social (15) } \\
\text { 9.8. Gestión (74) }\end{array}$ & $\begin{array}{l}\text { Accesibilidad universal, } \\
\text { seguridad, confort, } \\
\text { contaminación }\end{array}$ \\
\hline
\end{tabular}

Fuente: elaboración propia.

La siguiente sección contiene los principales hallazgos del análisis de los instrumentos normativos e indicativos, poniendo especial énfasis al lenguaje utilizado y las prioridades que se les asignan a las personas o medios de transporte que compiten por el uso del espacio público. Los resultados se estructuran en torno 
a las temáticas indicadas anteriormente, es decir, personas mayores y otros grupos vulnerados, el peatón, y los elementos del entorno que definen el espacio público peatonal. Para ejemplificar y desarrollar en profundidad puntos relevantes las siguientes secciones incluyen el desglose de algunas de las categorías descritas anteriormente y fragmentos de los documentos analizados.

\section{Resultados y discusión}

En general, el análisis muestra que las personas mayores se encuentran bastante ausentes en los instrumentos que definen el espacio público peatonal. Solo una de las categorías identificadas contiene referencias ligadas a las personas mayores (subcategoría 1.1 Rango etario, 8 menciones). La mayoría de las referencias a grupos vulnerados van dirigidas a las personas en situación de discapacidad y las potenciales barreras que enfrentan para acceder a la ciudad y participar en la sociedad (subcategoría 1.3 vulnerabilidad y discapacidad, 280 menciones). Las referencias ligadas al peatón son también escasas, solo una categoría (Cat. 2 Actividades de los peatones, 42 menciones) alude explícitamente a sus necesidades y requerimientos. Como se describirá más adelante, la mayor parte de las referencias al peatón encontradas apuntan a características del flujo peatonal (e.g., velocidad de desplazamiento) o a los conflictos con el transporte motorizado (Cat. 3 Flujos y conflictos, 504 menciones). La mayor parte de los fragmentos identificados durante el análisis cubren al espacio público peatonal. Agrupados en cinco categorías, las casi 2500 menciones al espacio público peatonal abordan principalmente a las características de las superficies por las que circulan los peatones (Cat. 4 Superficies de circulación, 634 menciones), los dispositivos que salvan desniveles (e.g., escaleras) o permiten cruzar la calzada vehicular (Cat. 5 Elementos que dan continuidad al espacio público peatonal, 427 menciones) y los elementos verticales (e.g., luminarias, señaléticas) que se ubican en el espacio peatonal (Cat. 6 Elementos verticales del espacio público peatonal, 396 menciones). Otras categorías menos nutridas sobre el espacio público peatonal agrupan las recomendaciones sobre las características que debiesen tener las fachadas (Cat. 7 Bordes del espacio público peatonal, 177 menciones) u ofrecen definiciones sobre los distintos espacios de circulación (Cat. 8 Tipos de espacios públicos y privados, 326 menciones). En una categoría adicional (Cat. 9 Atributos y beneficios del espacio público, 472 menciones) se agruparon los variados atributos y beneficios del espacio público peatonal, sin embargo, conviene destacar que esta categoría en específico se encuentra mayoritariamente alimentada por instrumentos recientes (Ministerio de Planificación, 2010) y manuales indicativos (PNUD y MINVU, 2017).

Los instrumentos muestran una clara evolución en sus enfoques. Los más antiguos (MINVU, 1992; MINVU, 2009) se enfocan en otorgar continuidad a los espacios del automóvil y asegurar la fluidez del tráfico. De esta forma, los lineamientos de aquellos instrumentos tienden a apuntar a aquellos espacios que pueden interrumpir el tránsito (e.g., cruces). El peatón causa "demoras" (MTT, 2015) y a menudo debe ajustarse a los tiempos (e.g., tiempos de cruce) y espacios (e.g., anchos de cruces) que causan menos conflictos con el transporte motorizado. En contraste, instrumentos nuevos (Gobierno de Chile y PNUD, 2014, MINVU, 2016; MTT, 2018), revisados recientemente (Ministerio de Planificación, 2010) o indicativos (SERVIU RM, 2013; PNUD y MINVU, 2017; MINVU, 2018) se enfocan en derechos inherentes de las personas (e.g., vida independiente) o en aquellos cuyo ejercicio depende del acceso a la ciudad (e.g., participación en la sociedad). A pesar de este cambio, el análisis evidencia que estos nuevos enfoques aún no están incluidos en los instrumentos que son vinculantes (MINVU, 1976; MINVU, 1992; MINVU, 2009; MTT, 2015) y que, por ende, tienen mayor incidencia en la construcción del espacio público peatonal. La mirada dominante sigue considerando a las personas que no utilizan transporte motorizado como una potencial fuente de conflicto que, de alguna manera, debe ser segregada.

Las personas que se desplazan a pie, en sillas de ruedas o en otro medio no-motorizado que no sean ciclos se "confinan" en los retazos que deja el espacio que se otorga al transporte motorizado. La presencia de cualquier amenidad (e.g., bancas) para los peatones queda supeditada a la existencia de espacios remanentes que podrían quedar sin un uso claro luego de trazar una calzada y una vereda de anchos continuos. Este espacio remanente se encuentra escasamente normado en los instrumentos y, por lo tanto, 
su existencia depende del agente desarrollador o del ancho que estipulan los instrumentos de planificación para algunas calles de relevancia metropolitana. En su mayoría, las calles se ajustan a los mínimos permitidos que, como muestra la Figura 1, incluyen calzadas de 7 metros (sobredimensionadas) y una vereda de 1.2 metros que puede incluso reducirse a 1 metro en barrios de vivienda social (MINVU, 1992), estando claramente sub-dimensionada.

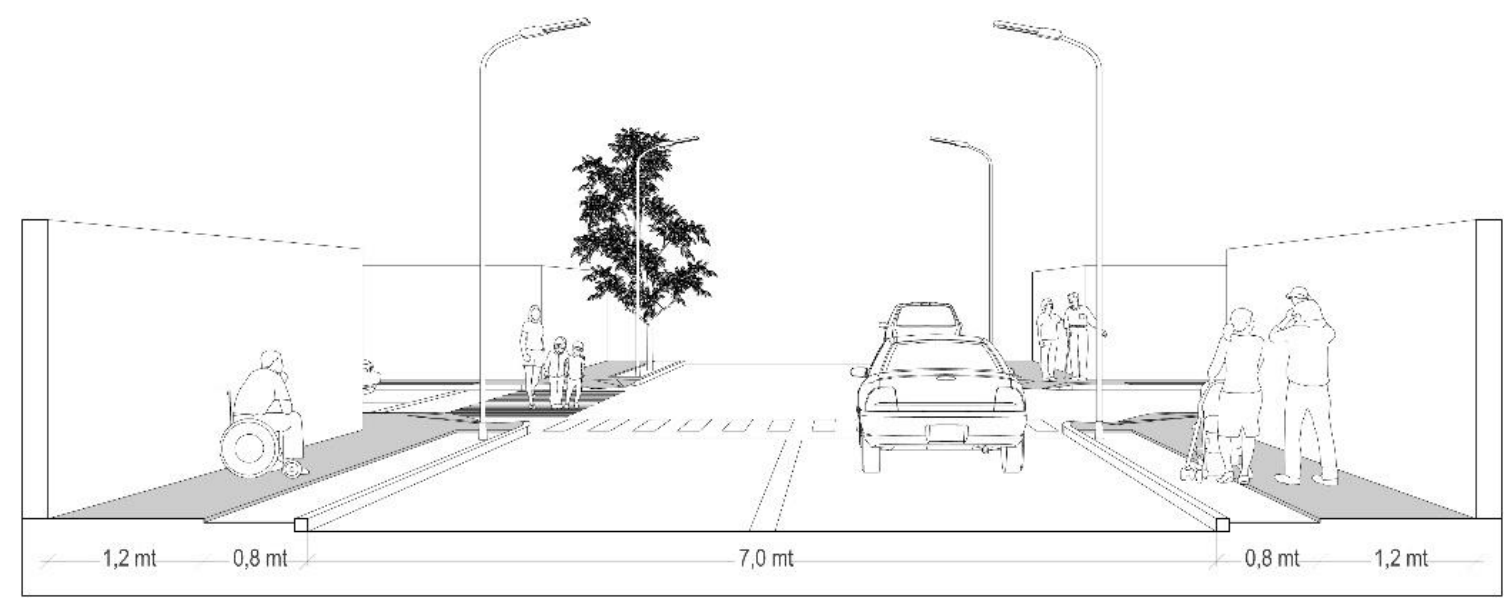

Figura 1 - Calle 'mínima' según los instrumentos normativos chilenos. Fuente: elaboración propia.

La imagen muestra la insuficiencia de los instrumentos en una serie de materias que han probado ser relevantes para la experiencia de las personas que se trasladan a pie. La vida pública es mencionada sólo una ocasión. A pesar de que afecta con fuerza a la población chilena (Dammert, 2014; Layera et al., 2020), el miedo al crimen es referido en fragmentos de un solo instrumento (MINVU, 2009). Otros aspectos que, de distintas maneras, afectan la experiencia y la calidad del viaje de los peatones (e.g., paisaje) siguen patrones similares y apenas aparecen en los instrumentos normativos analizados. Además, como muestra la definición de zona peatonal según el "Manual de recomendaciones para el diseño de elementos de infraestructura vial urbana" o REDEVU (MINVU, 2009), las alusiones a menudo se reducen a frases genéricas cuyo alcance real parece ser limitado:

Las zonas peatonales: aceras, calles peatonales, paseos, plazas, plazoletas, islas-refugio y el entorno a las esquinas, son espacios que surgen a partir de la vialidad y que se unen a parques y otras zonas comunes de una ciudad para configurar un escenario principal de la vida pública. [...]. En efecto, además de ser dichas zonas [peatonales] el nexo físico de los establecimientos comerciales y de servicio con la ciudadanía, ellas también sirven, apenas un diseño adecuado lo permite, para que los habitantes las usen de diversos modos: como lugar de encuentro, de esparcimiento y hasta de identificación si ellas consiguen generar ambientes que reflejen un espíritu urbano peculiar (MINVU, 2009, p. 83).

Gran parte de los instrumentos de carácter normativo busca establecer estándares mínimos de la infraestructura dedicada a los desplazamientos no vehiculares y resolver los potenciales conflictos entre los peatones y el transporte motorizado (i.e., accidentes). En el análisis se identificaron 94 referencias a estándares mínimos de las veredas (e.g., ancho, pendiente). En tanto que el número de fragmentos que aluden a las características de los cruces peatonales son igualmente altas (270 menciones). Sin embargo, como se abordará en la próxima sección (Sección 4.1), el elevado número de menciones no implica que los espacios sean particularmente amigables con las personas que, como las personas mayores, son más vulneradas.

\section{Las personas mayores y otros grupos vulnerados}

A pesar de que el término actualmente recomendado por la Convención Interamericana de Protección de los Derechos de las Personas Mayores (OEA, 2015) y el estado chileno (MINSAL, 2018) para referirse a las personas de edad avanzada es "persona mayor", no se encontró ninguna sección o frase en los diez 
instrumentos normativos que contuviera exactamente tal término. Los once fragmentos que fueron identificados en total que fueron asociados a las personas mayores aluden al proceso de envejecimiento o contienen referencias a conceptos que comúnmente se usan como sinónimos (e.g., adulto mayor, anciano). De esos once fragmentos, cuatro referencian explícitamente a las personas mayores al caracterizar los desafíos futuros que deberán enfrentar las ciudades chilenas debido al rápido envejecimiento poblacional (Gobierno de Chile y PNUD, 2014; MINSAL, 2015). El resto de los fragmentos son descripciones genéricas que incluyen a las personas mayores en un amplio grupo de personas con dificultades de desplazamiento y que son acompañadas por recomendaciones que buscan disminuir los obstáculos que podrían encontrar en las rutas (MINVU 2009; SERVIU RM, 2013; MTT, 2015). Este grupo incluye, además de personas mayores, infantes y niños, mujeres y embarazadas, personas que sufren de obesidad, que se encuentran en rehabilitación quirúrgica y otras personas cuyos requerimientos y necesidades son variadas (Figura 2).

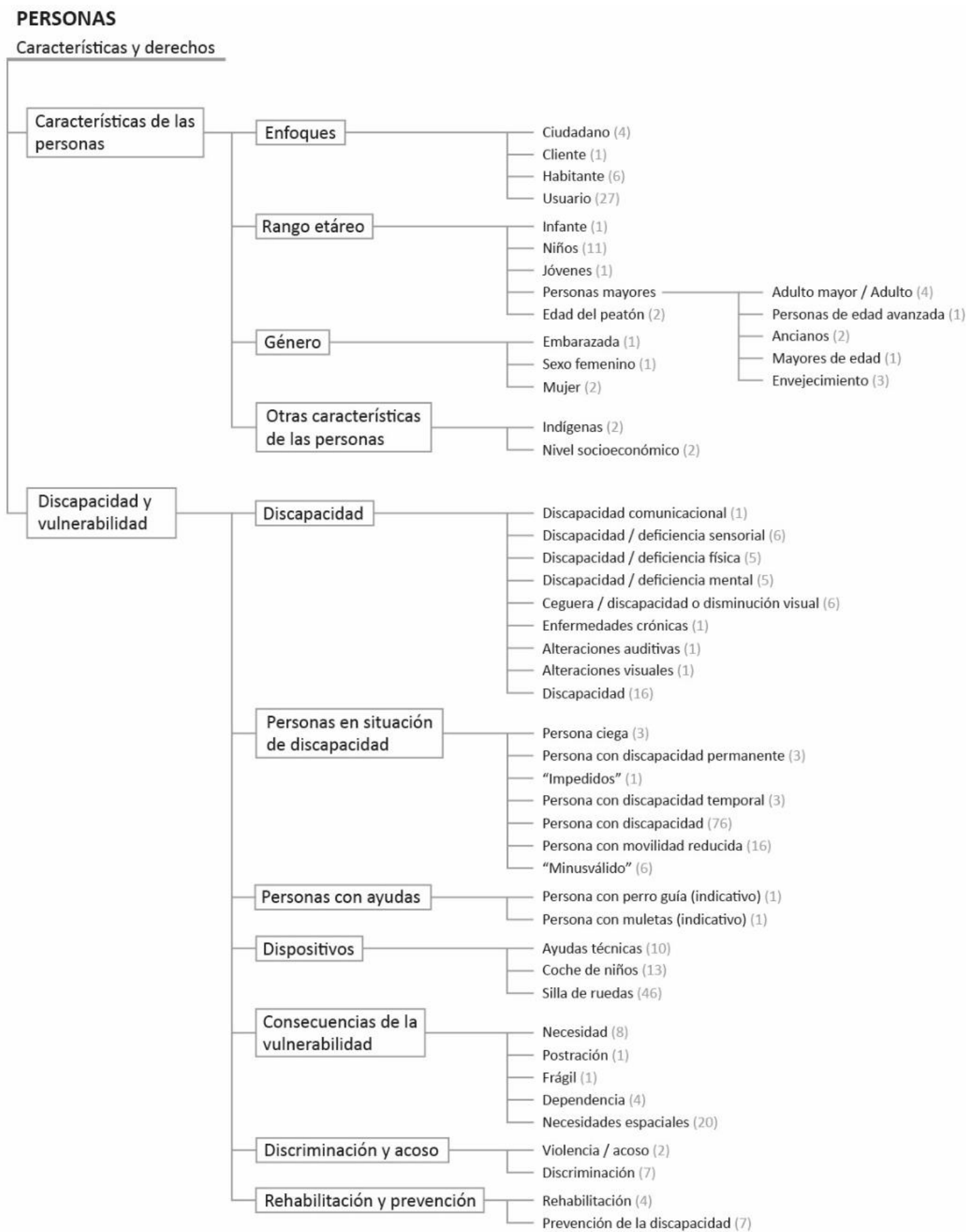

Figura 2 - Desglose categoría 1 - Personas: características y derechos. Fuente: elaboración propia. 
No solamente las personas mayores son desatendidas en las normativas y recomendaciones (en total 8 menciones). Los niños e infantes son mencionados solamente 12 veces, los indígenas 2 veces, y las mujeres sólo 4 veces. Temas de violencia, acoso y discriminación son mencionados únicamente 9 veces en todos los documentos, siendo en la mayoría de los casos fragmentos asociados a personas en situación de discapacidad. Como muestra la Figura 2, los instrumentos normativos e indicativos reconocen las distintas formas de discapacidad (e.g., auditiva, comunicacional), dispositivos de apoyo (e.g., ayudas técnicas), sus consecuencias (e.g., postración, dependencia) e incluso problemas de la esfera socio-cultural como los estigmas y el acoso. Particularmente desde la promulgación de la ley "sobre igualdad de oportunidades e inclusión social de personas con discapacidad" (Ministerio de Planificación, 2010), también se observó que los instrumentos recientes destacan y reconocen derechos consagrados universalmente (ONU, 2006) y han tendido a corregir una serie de conceptos discriminatorios. De esta manera, mientras que en el REDEVU (MINVU, 2009) se encontraron apelativos despectivos como "minusválidos" (6 menciones) o "impedidos" (1 mención), instrumentos recientes (Ministerio de Planificación, 2010; MINVU, 2016) utilizan términos recomendados por tratados y convenciones internacionales (Gobierno de Chile, 2017). En contraste con otros grupos vulnerados (entre ellos, las personas mayores), los instrumentos analizados profundizan en las personas en situación de discapacidad y basan una parte importante de sus recomendaciones para el diseño de los espacios en sus necesidades. De hecho, como muestran los siguientes ejemplos, la silla de ruedas es comúnmente la unidad que define los estándares "mínimos" (e.g., anchos, pendientes) de las veredas, los cruces, la ubicación de las amenidades (e.g., bancas) y equipamientos (e.g., paradas de buses) y otros aspectos relevantes de los espacios públicos peatonales:

A uno o a ambos costados [de bancos o escaños], deberá proveerse un espacio libre horizontal de 0,90 $\mathrm{m}$ por 1,20 m para que se pueda situar una persona con discapacidad en silla de ruedas (MINVU, 1992, p. 2-9).

El área de aproximación [a una caseta telefónica] debe estar libre de obstáculos y tener dimensiones mínimas de 0,80 m por 1,20 m para permitir una silla de ruedas (MINVU, 1992, p. 2-9).

La señalización vertical que identifica al paradero estará ubicada de forma que no obstaculice el acceso al paradero ni el giro en $360^{\circ}$ de una silla de ruedas (MINVU, 1992, p. 2-10).

La relativa relevancia que se da a las personas en situación de discapacidad en los instrumentos analizados tiende, no obstante, a limitarse a la eliminación de barreras y, particularmente, a los desniveles que puede haber en el espacio público peatonal. Otros requerimientos de las personas en situación de discapacidad y de otros grupos vulnerados se encuentran poco atendidos. Por ejemplo, el Manual de Señalización de Tránsito (MTT, 2015) indica que la velocidad promedio de los peatones "depende de las características de las personas, principalmente su edad y las eventuales limitaciones de movilidad que presenten" (p. 37) y recomienda diseñar cruces y atraviesos considerando velocidades de entre 1,1 y 0,9 metros por segundo, siendo 1,1 m/seg la velocidad de la población en general y 0,9 m/seg la velocidad de las personas mayores, niños y personas con movilidad reducida. Sin embargo, tal como indica la literatura, el rango inferior supera ampliamente la velocidad que alcanzan algunas personas mayores (entre 0,44 y 1,67 $\mathrm{m} / \mathrm{seg}$. según Espinosa et al., 2015), las personas en sillas de ruedas (entre 0,5 y 0,8 m/seg. según Sonenblum et al., 2012) o con ayudas técnicas (0,66 m/seg. según Arango y Montufar, 2008)².

Una situación similar se observa en las intersecciones viales, en donde los amplios radios de giro recomendados (15 y 50 metros en calles locales y de servicio respectivamente, ver MINVU, 2009) prolongan la distancia a cruzar por las personas que se trasladan a pie o con ayudas técnicas y permiten al transporte motorizado mantener velocidades relativamente altas. Tampoco existen claras recomendaciones que respondan a las necesidades de las personas con dificultades cognitivas o sensoriales; que recojan aspectos

\footnotetext{
2 La situación tiende a agravarse aún más al considerar que muchos de los cruces que existen en las ciudades de Chile se diseñan considerando el rango superior de 1.1 m/seg. por segundo (Laboratorio de Innovación Pública, 2018).
} 
claves de la caminata (e.g., intercambio social) o necesidades específicas de los grupos vulnerados como el juego (niños) o el descanso (personas mayores). Como se desarrollará en la próxima sección, los instrumentos tienden a minimizar las necesidades de las personas a pie y con frecuencia basan sus recomendaciones en un peatón "promedio".

\section{El peatón}

El análisis de los instrumentos mostró que el peatón tiende a ser simplificado. Así, se encontraron sólo 33 fragmentos que aluden a las actividades que los peatones llevan a cabo en el espacio público, cinco indicando que desplazarse a pie es clave para acceder al trabajo y para proveerse, diez apuntando a aspectos recreativos y siete referenciando a las interacciones sociales que ocurren mientras se camina (Figura 3). Otras diez referencias apuntan al descanso y la espera y sólo un fragmento identificado menciona actividades deportivas. El análisis también reveló que las referencias a las actividades peatonales son, en su mayoría, parte de los objetivos generales de los instrumentos y no se traducen en medidas, recomendaciones o lineamientos que permitan generar espacios públicos más amables con las personas que se desplazan a pie.

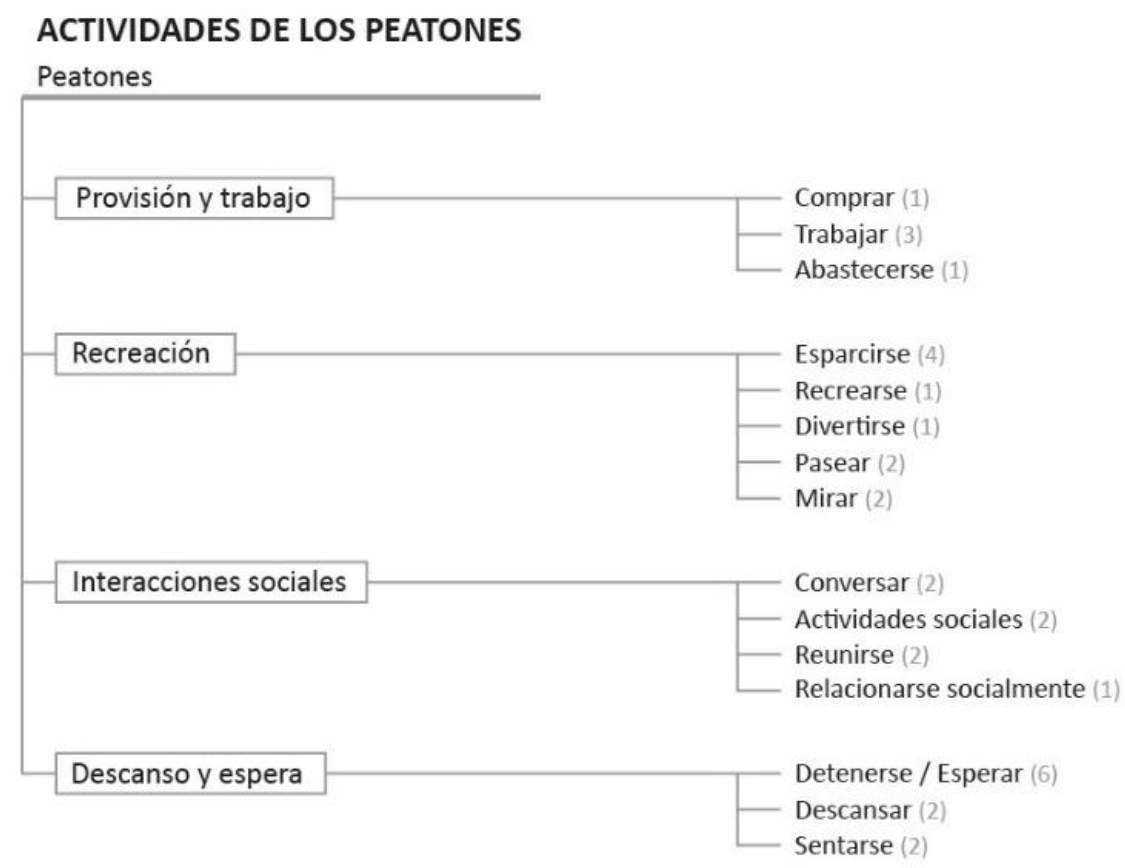

Figura 3 - Desglose categoría 2 - Actividades de los peatones. Fuente: elaboración propia.

En los instrumentos analizados el peatón es comúnmente reducido a uno de los muchos flujos que compiten por el espacio de las calles. Lo describen como un flujo en constante movimiento (MINVU, 2009; MTT, 2015) y basan sus sugerencias principalmente en el volumen (11 referencias), la velocidad (14 referencias) y la densidad peatonal (15 referencias). De acuerdo a aquellos parámetros se recomiendan espacios que resultan "generosos" para flujos en constante movimiento, pero "angostos" cuando alguna persona, por distintas razones, los interrumpe. Por ejemplo, y tal como se verifica en la literatura existente (Herrmann-Lunecke, 2016), las dimensiones de las veredas de las ciudades chilenas obligan a las personas a circular fuera de ellas, en fajas irregulares ocupadas por servicios, árboles y otros equipamientos, o a descender a las calzadas vehiculares si alguien, como una persona mayor, camina a menor velocidad, se detiene o transita en la dirección opuesta (ver Figura 1). Lo mismo ocurre cuando las personas caminan acompañadas o asistiendo a un tercero (e.g., madres con infantes); aquellos conflictos no son recogidos en las directrices que se otorgan. Así, el REDEVU (MINVU, 2009) define como ancho mínimo 2 metros para las 
veredas, ancho que según el manual permitiría el cruce de dos personas en sillas de ruedas³, pero permite la reducción de la métrica a 1.2 metros en las veredas de calles locales que componen la mayor parte de los barrios de las ciudades chilenas:

Se considera que el ancho mínimo recomendable para las veredas es de $2 \mathrm{~m}$., que corresponde al espacio necesario para que se crucen dos personas que lleven paquetes, coches de niños o que circulen en silla de ruedas [...]. Este ancho mínimo puede reducirse a 1,2 m. en calles locales (MINVU, 2009; p. 90).

El peatón es una entidad abstracta y estandarizada en constante movimiento, caracterizado por una velocidad promedio alta; en raras ocasiones se singularizan situaciones o necesidades específicas de las personas de acuerdo a su edad, género u otro factor relevante. De hecho, como se describió en la sección anterior, las referencias a aquellas características son casi inexistentes en los instrumentos estudiados. El peatón es entendido también como una suma de promedios (e.g., velocidades, quema de calorías) que a menudo redunda en espacios públicos peatonales que excluyen a aquellos que escapan de la "norma".

\section{El espacio público peatonal}

En concordancia con lo expuesto en las secciones anteriores, la mayor parte de los lineamientos que los instrumentos analizados proporcionan se enfocan en tres aspectos del espacio público peatonal: los conflictos entre el peatón y el transporte motorizado, la eliminación de desniveles en los suelos (a partir de escaleras, rampas), y la generación de una franja peatonal continua libre de obstáculos. En detalle, se identificaron 270 fragmentos que recogen los conflictos peatón-transporte motorizado y aluden a los tipos de cruces peatonales (103 menciones), los atributos de cruces (24 menciones) y los elementos que los conforman (104 menciones). Como muestra el desglose de la categoría 5, en la Figura 4, otro número importante de fragmentos (157) apunta a los elementos del espacio peatonal que podrían representar barreras para las personas en situación de discapacidad. Finalmente, 17 fragmentos persiguen asegurar la existencia de espacios peatonales continuos.

\footnotetext{
${ }^{3}$ En otros países, como por ejemplo Alemania, se definen 2,5 metros para el cruce de dos personas en sillas de ruedas (HerrmannLunecke, 2016).
} 


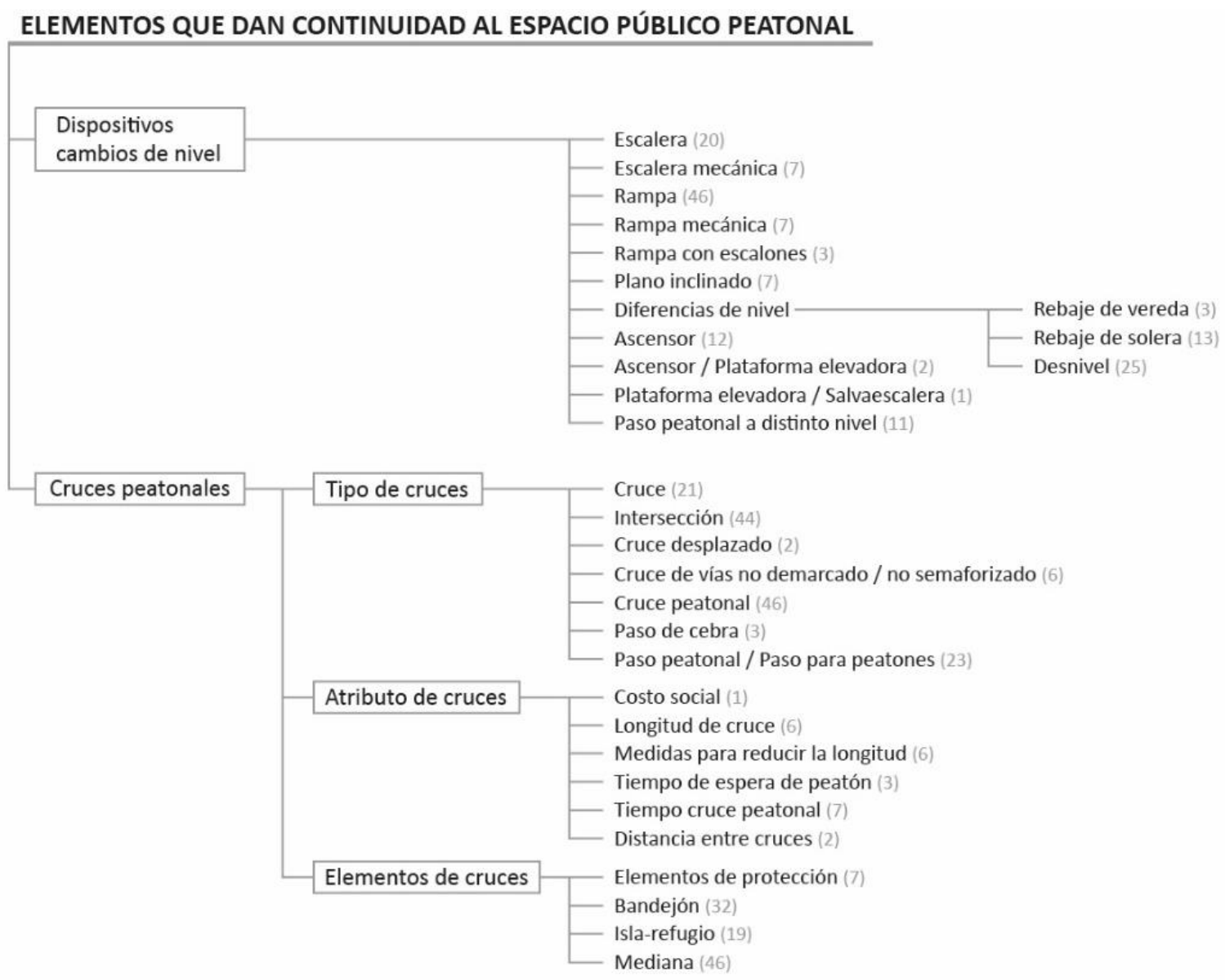

Figura 4 - Desglose categoría 5 - Elementos que dan continuidad al espacio público peatonal. Fuente: elaboración propia.

Los instrumentos en su mayoría buscan proveer a las personas de espacios públicos peatonales "funcionales". Las recomendaciones asociadas a la franja peatonal, llamada indistintamente vereda, faja o banda continua, usualmente se enfocan en la materialidad de la superficie (35 menciones) y el ancho (29 menciones). La misma situación se repite con los fragmentos asociados a superar los desniveles en el suelo que ponen énfasis en las características materiales y las dimensiones que debiesen tener las rampas (45 menciones), las escaleras (20 menciones) y los ascensores (12 menciones) presentes en el espacio público peatonal. En el caso de los cruces, el foco está en las dimensiones de la mediana (46 menciones) y las "islas refugio" (20 menciones). Poca atención se le da a la calidad del espacio público peatonal. Es más, los instrumentos tienden a minimizar la relevancia de aquellos elementos o características del espacio público peatonal que puedan afectar positivamente la experiencia de las personas, como son los árboles y los usos en los bordes de las veredas (Herrmann-Lunecke et al., 2020). Se observa que los elementos "verticales", incluyendo árboles, luminarias, amenidades (e.g., bancas) e infraestructura (e.g., hidrantes) son recurrentemente representados como "obstáculos" que pueden restringir el espacio disponible para la faja continua peatonal (MINVU, 1992; 2009) u obstruir la visibilidad de los semáforos (MTT, 2015). En muy pocos fragmentos se comprende que estos elementos verticales pueden enriquecer el espacio público peatonal y afectar la percepción de inseguridad ( 2 menciones), la comodidad ( 7 menciones) y, en general, la experiencia y calidad de los traslados a pie (sin menciones). Por ejemplo, los servicios higiénicos aparecen mencionados en 2 ocasiones, mientras que las bancas o asientos son solo mencionados 8 veces a pesar de la relevancia que tienen para las personas mayores (González, 2004).

Asimismo, la reconocida relación entre la vitalidad, la seguridad y la diversidad del espacio público y la configuración de las fachadas (Jacobs, 1961; Gehl, 1987) aparece vagamente referida en instrumentos normativos y no tiene implicancias en los lineamientos que se sugieren (MINVU, 1992; MINVU, 2009). Instrumentos recientes de carácter indicativo y de escaso impacto real en la construcción de los espacios públicos peatonales exploran aquellos aspectos en profundidad (PNUD y MINVU, 2017), pero la relevancia 
que se le da a los bordes del espacio público peatonal en los instrumentos normativos se relaciona casi exclusivamente con las potenciales interrupciones que las salidas vehiculares y peatonales de casas y edificios u otras infraestructuras (e.g., aguas lluvias) pueden generar en la continuidad de la franja peatonal.

\section{Conclusiones}

El artículo analiza en qué medida los instrumentos de planificación urbana abordan la caminata en la vejez y consideran a las personas mayores en el diseño del espacio público peatonal en Chile. Los resultados indican que las personas mayores y otros grupos vulnerados como niños y mujeres son poco consideradas en los instrumentos normativos existentes. Sus necesidades y requerimientos usualmente no son recogidos en espacios públicos diseñados para un peatón abstracto, promedio y en movimiento "rápido" que, además, es a menudo representado como una fuente de conflicto para el tránsito motorizado.

Si bien instrumentos normativos (Gobierno de Chile y PNUD, 2014, MINVU, 2016; MTT, 2018) e indicativos recientes (SERVIU RM, 2013; PNUD y MINVU, 2017; MINVU, 2018) ponen en el centro las necesidades de las personas y, en particular, de los grupos vulnerados, sus novedosas aproximaciones aún no se traducen en lineamientos que permitan mejorar el espacio público peatonal. La mayor parte de los instrumentos que determinan las características del espacio público peatonal de las ciudades chilenas (MINVU, 1976; MINVU, 1992; MINVU, 2009; MTT, 2015) todavía se enfocan en su funcionalidad y en la provisión de espacios que permitan desplazamientos "fluidos". La calidad del espacio público peatonal y los elementos que pueden afectar la experiencia de las personas son recogidos en raras ocasiones en los instrumentos analizados. Aunque la naturaleza del análisis expuesto en este artículo no permite avanzar sobre los impactos de las recomendaciones que otorgan los instrumentos sobre la movilidad de las personas mayores, los hallazgos de diversos trabajos (Mitra et al., 2015; Cano y Sánchez-González, 2019; Espinosa et al., 2015; Herrmann-Lunecke et al., 2021) indican que el espacio público diseñado para un peatón promedio y enfocado en la funcionalidad y no en la calidad podría estar dificultando los desplazamientos de las personas mayores, favoreciendo la inmovilidad e impidiendo su plena participación en la sociedad. Elementos señalados como relevantes para la caminata de las personas mayores tales como veredas más anchas o cruces semafóricos largos (Herrmann-Lunecke et al., 2021), no son considerados en las normativas chilenas y son escasamente mencionados.

Finalmente, los hallazgos del trabajo, y en particular las categorías identificadas, permiten sugerir algunas acciones para mejorar el panorama actual. La pobreza de ciertas categorías (Cat 1 Personas: características y derechos; Cat 2 Actividades de los peatones) evidencian vacíos que debiesen ser revisados en profundidad y cubiertos por nuevos instrumentos o por profundas modificaciones de los existentes. Sólo el hecho de "mencionar" con mayor frecuencia a las personas mayores podría ayudar a visibilizar sus muy diversas necesidades (e.g., menores velocidades, necesidad de descanso, mayor propensión a caídas). Otras categorías pueden traducirse a criterios, lineamientos e instrumentos que permitan evaluar cuan adecuados son los espacios urbanos para las personas mayores y otros grupos vulnerados. Las categorías 5 (Elementos que dan continuidad al espacio público peatonal), 6 (Elementos verticales del espacio público peatonal) y 7 (Bordes del espacio público peatonal) apuntan a la funcionalidad de los espacios y podrían ayudar a definir nuevos estándares para las veredas (por ejemplo, ancho mínimo de al menos 2,5 metros, adecuada mantención), los cruces (tiempos semafóricos considerando velocidades de 0,5 m/seg) y los demás elementos del espacio peatonal (rampas, escaleras). Mientras que la Cat. 9 (Atributos y beneficios del espacio público) puede ayudar a comprender de mejor manera la calidad de los espacios y traducirse en una mayor atención al paisaje (e.g., vegetación, árboles), al confort (bancas y espacios para el descanso) y otros aspectos que forman parte de la experiencia de la caminata. Consideraciones de tal naturaleza podrían ayudar a enfrentar el envejecimiento de la población que ya se vislumbra como uno de los principales desafíos de las ciudades del siglo XXI. 


\section{Agradecimientos}

Esta investigación fue financiada por ANID Fondecyt Regular Nㅜ 1200527.

\section{Declaración de disponibilidad de datos}

El conjunto de datos que respalda los resultados de este artículo está disponible en SciELO DATA y se puede acceder a él en https://doi.org/10.48331/scielodata.FEC3AC

\section{Referencias}

Abusleme, M., \& Caballero, M. (2014). Maltrato a las personas mayores en Chile: haciendo visible lo invisible. Santiago de Chile: SENAMA.

Adams, C. (2012). Maltrato en el adulto mayor institucionalizado: Realidad e invisibilidad. Revista Médica Clínica Las Condes, 23(1), 84-90.

Albala, C., Sánchez, H., Lera, L., Angel, B., \& Cea, X. (2011). Efecto sobre la salud de las desigualdades socioeconómicas en el adulto mayor: Resultados basales del estudio expectativa de vida saludable y discapacidad relacionada con la obesidad (Alexandros). Revista médica de Chile, 139(10), 1276-1285.

Apella, I., Packard, T., Zumaeta, M., \& Joubert, C. (2019). Retos y oportunidades del envejecimiento en Chile. The World Bank. Aranco, N., Stampini, M., Ibarrarán, P., \& Medellín, N. (2018). Panorama de envejecimiento y dependencia en América Latina y el Caribe. Resumen de Políticas. Washington DC, Estados Unidos.

Arango, J., \& Montufar, J. (2008). Walking speed of older pedestrians who use canes or walkers for mobility. Transportation Research Record, 2073(1), 79-85.

Arango, M., Páez, C., Reis, S., Brownson, R., \& Parra, D. (2013). Association between the perceived environment and physical activity among adults in Latin America: a systematic review. International Journal of Behavioral Nutrition and Physical Activity, 10(1), 1-9.

Banco Mundial (2018). Esperanza de vida al nacer, total (años) - Chile. Recuperado el 15 de enero de 2021, de https://datos.bancomundial.org/indicador/SP.DYN.LE00.IN?locations=CL

Barnett, D., Barnett, A., Nathan, A., Van Cauwenberg, J., \& Cerin, E. (2017). Built environmental correlates of older adults' total physical activity and walking: a systematic review and meta-analysis. International journal of behavioral nutrition and physical activity, 14(1), 1-24.

Barrantes, M. (2006). Género, vejez y salud. Acta bioethica, 12(2), 193-197.

Bravo-Segal, S. (2018). Edadismo en medios masivos de comunicación: una forma de maltrato discursivo hacia las personas mayores. Discurso \& Sociedad, (1), 1-28.

Caldeira, T. (2017). Peripheral urbanization: Autoconstruction, transversal logics, and politics in cities of the global south. Environment and Planning D: Society and Space, 35(1), 3-20.

Cano, E., \& Sánchez-González, D. (2019). Espacio público y sus implicaciones en el envejecimiento activo en el lugar. Cuadernos de Arquitectura y Asuntos Urbanos.

Clarke, P., Ailshire, J. A., Bader, M., Morenoff, J. D., \& House, J. S. (2008). Mobility disability and the urban built environment. American journal of epidemiology, 168(5), 506-513.

Comisión Económica para América Latina y el Caribe - CEPAL (2007). Declaración de Brasilia. Brasilia: CEPAL.

Corporación Ciudad Accesible, \& Boudeguer \& Squella ARQ (2010). Manual de accesibilidad universal. Santiago de Chile: Corporación Ciudad Accesible.

Dammert, L. (2014). La relación entre confianza e inseguridad: el caso de Chile. Revista Criminalidad, 56(1), $189-207$.

Deka, D., \& Brown, C. (2020). Does the pathway to transportation walking for older adults run through recreational walking?. Travel behaviour and society, 20, 51-61. 


\section{Caminata y vejez}

Demerath, L., \& Levinger, D. (2003). The social qualities of being on foot: A theoretical analysis of pedestrian activity, community, and culture. City \& Community, 2(3), 217-237.

Espinosa, R., Ibaceta, A., Meza, D., Silva, J., \& Urzúa, J. (2015). ¿Los tiempos de los semáforos ubicados en Santiago de Chile, permiten que las personas adultas mayores crucen las calles con seguridad? En el $6^{\circ}$ Encuentro Anual Sociedad Chilena de Políticas Públicas. Santiago de Chile: Sociedad Chilena de Políticas Públicas.

Fadda, G., \& Cortés, A. (2009). Hábitat y adulto mayor: el caso de Valparaíso. Revista Invi, 24(66), 89-113.

Ferrer, S., Ruiz, T., \& Mars, L. (2015). A qualitative study on the role of the built environment for short walking trips. Transportation research part F: traffic psychology and behaviour, 33, 141-160.

Figueroa, C. y Forray, R. (2015). Movilidad femenina: los reveses de la utopía socio-espacial en las poblaciones de Santiago de Chile. Revista de Estudios Sociales, (54), 52-67.

Figueroa, C., Hodgson, F., Mullen, C., y Timms, P. (2019). Walking through deprived neighbourhoods: meanings and constructions behind the attributes of the built environment. Travel behaviour and society, 16, 171-181.

Fossey, E., Harvey, C., McDermott, F., \& Davidson, L. (2002). Understanding and evaluating qualitative research. Australian \& New Zealand Journal of Psychiatry, 36(6), 717-732.

Fuentes-García, A., Sánchez, H., Lera, L., Cea, X., \& Albala, C. (2013). Desigualdades socioeconómicas en el proceso de discapacidad en una cohorte de adultos mayores de Santiago de Chile. Gaceta Sanitaria, 27(3), 226-232.

Gaete-Reyes, M. (2017). Discapacidad y hábitat residencial: una emergencia en Chile. En W. Imilan, J. Larenas, G. Carrasco \& S. Rivera (Eds.), ¿Hacia dónde va la vivienda en Chile? Nuevos desafíos en el Hábitat Residencial (p. 281-295). Santiago de Chile: Adrede Editora.

Gajardo, J., Navarrete, E., López, C., Rodríguez, J., Rojas, A., Troncoso, S., \& Rojas, A. (2012). Percepciones de personas mayores sobre su desempeño en el uso de transporte público en Santiago de Chile. Revista Chilena de Terapia Ocupacional, 12(1), 88-102.

Garin, N., Olaya, B., Miret, M., Ayuso-Mateos, J., Power, M., Bucciarelli, P., \& Haro, J. (2014). Built environment and elderly population health: a comprehensive literature review. Clinical practice and epidemiology in mental health, 10, 103.

Gehl, J. (1987). Life between buildings: using public space. New York: Van Nostrand Reinhold.

Gobierno de Chile, \& Programa de las Naciones Unidas para el Desarrollo - PNUD (2014). Política Nacional de Desarrollo Urbano (PNDU). Gobierno de Chile.

Gobierno de Chile (2017). Uso de lenguaje inclusivo. Persona en situación de discapacidad. Gobierno de Chile.

Gomes, G., Reis, R., Parra, D., Ribeiro, I., Hino, A., Hallal, P., Malta, D., \& Brownson, R. C. (2011). Walking for leisure among adults from three Brazilian cities and its association with perceived environment attributes and personal factors.

International Journal of Behavioral Nutrition and Physical Activity, 8(1), 1-8.

Gómez, L., Parra, D., Buchner, D., Brownson, R., Sarmiento, O., Pinzón, J., Ardila, M., Moreno, J., Serrato, M., \& Lobelo, F. (2010). Built environment attributes and walking patterns among the elderly population in Bogotá. American journal of preventive medicine, 38(6), 592-599.

González, S. (2004). Actividades y salud en el espacio público: El servicio higiénico, un equipamiento urbano no asumido. El caso del centro de Santiago. Revista de Urbanismo, (10), 34-72.

Herrmann-Lunecke, M. (2016). Instrumentos de planificación y diseño urbano para promover al peatón en las ciudades chilenas. Un estudio comparado entre Chile y Alemania. Urbano, 48-57.

Herrmann-Lunecke, M., Mora, R., \& Véjares, P. (2020). Identificación de elementos del paisaje urbano que fomentan la caminata en Santiago. Revista de Urbanismo, 43, 4-25.

Herrmann-Lunecke, M. G., Mora, R., \& Vejares, P. (2021). Perception of the built environment and walking in pericentral neighbourhoods in Santiago, Chile. Travel behaviour and society, 23, 192-206.

Higueras, E., Román, E. \& Fariña, J. (2021). Guidelines for Healthier Public Spaces for the Elderly Population: Recommendations in the Spanish Context. En Handbook of Quality of Life and Sustainability (pp. 35-51). Springer, Cham.

Ingold, T., \& Vergunst, J. (2008). Ways of walking: Ethnography and practice on foot. Ashgate Publishing, Ltd.

Instituto Nacional de Estadística - INE (2018). Estimaciones y proyecciones de la población de Chile 1992-2050. Total país. INE. 


\section{Caminata y vejez}

Jacobs, J. (1961). The death and life of great American cities. New-York: Vintage.

Laboratorio de Innovación Pública (2018). RedActiva: Fomentando la movilidad de los adultos mayores en la ciudad. Santiago de Chile: Laboratorio de Innovación Pública.

Layera, M., Otero, G., \& Perret, V. (2020). Inseguridad Percibida en los Barrios de Santiago de Chile: La Importancia del Bienestar Subjetivo. Dados, 63(1).

Lee, I. M., \& Buchner, D. M. (2008). The importance of walking to public health. Medicine \& Science in Sports \& Exercise, 40(7), S512-S518.

Lorimer, H. (2011). Walking: New forms and spaces for studies of pedestrianism. En T. Cresswell \& P. Merriman (Eds.), Geographies of mobilities: Practices, spaces, subjects (p. 19-34). Ashgate Publishing, Ltd.

Marín, P. (2007). Reflexiones para considerar en una política pública de salud para las personas mayores. Revista Médica de Chile, 135(3), 392-398.

Ministerio de Justicia (1984, 07 de febrero). Ley 18.290 - Ley de tránsito. Chile: Recopilación de la Contraloría General de la República. https://www.bcn.cl/leychile/navegar?idNorma=29708

Ministerio de Obras Públicas - MOP (1949, 20 de octubre). Ley 8.946 - Ley de pavimentación comunal. Chile: Boletín de Leyes y Decretos del Gobierno. https://www.bcn.cl/leychile/navegar?idNorma=25880

Ministerio de Planificación (2010, 10 de febrero). Ley 20.422 - Igualdad de oportunidades e inclusión social de personas con discapacidad. Chile: Diario Oficial. https://www.bcn.cl/leychile/navegar?idNorma=1010903

Ministerio de Salud - MINSAL (2015). Manual de prevención de caídas en el adulto mayor. Ministerio de Salud.

Ministerio de Salud - MINSAL (2016). Informe de Descripción de Programas Sociales. Más Adultos Mayores Autovalentes. Ministerio de Desarrollo Social y Familia.

Ministerio de Salud - MINSAL (2018). Nuevas expresiones para referirse a las personas mayores. Santiago de Chile: Ministerio de Salud.

Ministerio de Transportes y Telecomunicaciones - MTT (2015). Manual de Señalización de Tránsito. Ministerio de Transportes y Telecomunicaciones.

Ministerio de Transportes y Telecomunicaciones - MTT (2018, 10 de mayo). Ley 21.088 - Convivencia Medios de Transporte. Chile: Diario Oficial. https://www.bcn.cl/leychile/navegar?idNorma=1118358

Ministerio de Vivienda y Urbanismo - MINVU (1976, 13 de abril). Decreto con Fuerza de Ley 458 - Ley General de Urbanismo y Construcciones. Chile: Recopilación de la Contraloría General de la República.

https://www.bcn.cl/leychile/navegar?idNorma=13560

Ministerio de Vivienda y Urbanismo - MINVU (1992). Ordenanza General de Urbanismo y Construcciones. Ministerio de Vivienda y Urbanismo.

Ministerio de Vivienda y Urbanismo - MINVU (2009). Recomendaciones para el diseño de elementos de infraestructura vial urbana (REDEVU). Ministerio de Vivienda y Urbanismo.

Ministerio de Vivienda y Urbanismo - MINVU (2016, 04 de marzo). Decreto Supremo 50 - Accesibilidad Universal. Chile: Diario Oficial. https://www.bcn.cl/leychile/navegar?idNorma=1088117

Ministerio de Vivienda y Urbanismo - MINVU (2018). Guía de soluciones accesibles para espacios públicos y viviendas. Ministerio de Vivienda y Urbanismo.

Mitra, R., Siva, H., \& Kehler, M. (2015). Walk-friendly suburbs for older adults? Exploring the enablers and barriers to walking in a large suburban municipality in Canada. Journal of aging studies, 35, 10-19.

Nyman, S., Ballinger, C., Phillips, J. E., \& Newton, R. (2013). Characteristics of outdoor falls among older people: a qualitative study. BMC geriatrics, 13(1), 1-14.

O’Connor, C., \& Joffe, H. (2020). Intercoder reliability in qualitative research: debates and practical guidelines. International Journal of Qualitative Methods, 19.

Olivi, A., Fadda, G., \& Reyes, V. (2016). Movilidad urbana y calidad de vida de las personas mayores en una ciudad vertical. El caso de Valparaíso, Chile. Revista Márgenes Espacio Arte y Sociedad, 13(19), 38-47. 


\section{Caminata y vejez}

Organización de las Naciones Unidas - ONU (2003). Declaración Política y Plan de Acción Internacional de Madrid sobre el Envejecimiento. Nueva York: ONU.

Organización de las Naciones Unidas - ONU (2006). Convención sobre los Derechos de las Personas con Discapacidad y Protocolo Facultativo. ONU.

Organización de los Estados Americanos - OEA (2015). Convención Interamericana de Protección de los Derechos de las Personas Mayores. OEA.

Osorio, P., Torrejón, M. J., \& Vogel, N. (2008). Aproximación a un concepto de calidad de vida en la vejez. Escuchando a las personas mayores. Revista de Psicología, 17(1), 101-108.

Pontificia Universidad Católica de Chile - PUC-Chile, \& Caja Los Andes (2020). Encuesta Nacional Calidad de Vida en la Vejez 2019. Santiago de Chile: PUC.

Programa de las Naciones Unidas para el Desarrollo - PNUD, \& Ministerio de Vivienda y Urbanismo - MINVU (2017). La dimensión humana del espacio público. Ministerio de Vivienda y Urbanismo.

Salvo, G., Lashewicz, B. M., Doyle-Baker, P. K., \& McCormack, G. R. (2018). Neighbourhood built environment influences on physical activity among adults: A systematized review of qualitative evidence. International Journal of Environmental Research and Public Health, 15(5), 897.

Servicio de Vivienda y Urbanismo Región Metropolitana - SERVIU RM (2013). Diseño universal en el espacio público. Servicio de Vivienda y Urbanismo Región Metropolitana.

Servicio Nacional del Adulto Mayor - SENAMA (2019). Monitoreo y seguimiento oferta pública 2019. Nombre del programa: Envejecimiento Activo. Ministerio de Desarrollo Social y Familia.

Sonenblum, S., Sprigle, S. \& Lopez, R. (2012). Manual wheelchair use: bouts of mobility in everyday life. Rehabilitation research and practice.

Subsecretaría de Evaluación Social (2020). Documento de resultados: personas mayores, envejecimiento y cuidados. Santiago de Chile: Gobierno de Chile.

United Nations Department of Economic and Social Affairs - UN DESA (2015). Income Poverty in Old Age: An Emerging Development Priority. ONU.

United Nations Department of Economic and Social Affairs - UN DESA (2020). World population aging 2019. New York: ONU.

Vecchio, G., Castillo, B., \& Steiniger, S. (2020). Movilidad urbana y personas mayores en Santiago de Chile: el valor de integrar métodos de análisis, un estudio en el barrio San Eugenio. Revista de Urbanismo, (43), 26-45.

Waintrub, N. (2018). Children's Unaccompanied Trips: How do the interpretations given to the Built Environment affect children's unaccompanied trips? En AMPS Proceedings Series 13 (p. 100-110). Abu Dhabi: AMPS.

Warmoth, K., Lang, I. A., Phoenix, C., Abraham, C., Andrew, M. K., Hubbard, R. E., \& Tarrant, M. (2016). 'Thinking you're old and frail': a qualitative study of frailty in older adults. Ageing \& Society, 36(7), 1483-1500.

World Health Organization - WHO (2015). World report on ageing and health. World Health Organization

World Health Organization - WHO (2018). The Global Network for Age-friendly Cities and Communities. Looking back over the last decade, looking forward to the next. World Health Organization

World Health Organization - WHO (2020). Decade of healthy ageing: baseline report. World Health Organization.

Yen, I., Fandel Flood, J., Thompson, H., Anderson, L., \& Wong, G. (2014). How design of places promotes or inhibits mobility of older adults: realist synthesis of 20 years of research. Journal of aging and health, 26(8), 1340-1372.

Editor: Luís Alberto Salinas Arreortua

Recibido: 20 mar. 2021

Aprobado: 29 jul. 2021 